\title{
EDITORIAL
}

\section{A ENFERMAGEM E O SISTEMA DE SAÚDE}

Tereza Cristina Scatena Villa*

Silvana Martins Mishima*

A discussão da temática da enfermagem e sua articulação com outras práticas de saúde implica na compreensão da constituição de um campo de conhecimento e de intervenção sobre a realidade, que não se dá de modo estático e único, ao contrário, apresenta historicidade.

Assim, a enfermagem inserida nas práticas sanitárias em curso numa sociedade, num dado momento, repousa numa concepção do que representa sobre o processo saúde-doença naquele período, do modo como toma as necessidades presentes na sociedade e da forma como se articula ao processo de produção de serviços de saúde para atender tais necessidades.

O conhecimento da enfermagem vem se conformando em busca de uma intervenção de forma integrada na defesa da vida, no processo sofrer/adoecer/prevenir/promover/ a saúde individual e coletiva.

Esta concepção tem suscitado reflexões acerca dos caminhos que a enfermagem está percorrendo para instrumentalizar sua prática no sistema de saúde.

O desafio da enfermagem e de outras práticas de saúde na perspectiva de construção do sistema de saúde tem sido ocupar espaços, a fim de viabilizar os preceitos constitucionais:

- o conceito de saúde como direito universal derivado do exercício de uma cidadania plena;

- a criação de um Sistema Único de Saúde organizado segundo diretrizes de descentralização com comando único em cada esfera de governo, o atendimento integral e participação popular.

- a integração da saúde no espaço mais amplo da seguridade social.

* Professora Doutora do Departamento de Enfermagem Materno-Infantil e Saúde Pública da Escola de Enfermagem de Ribeirão Preto da Universidade de São Paulo 
Esse projeto a ser construído busca organizar o atendimento à saúde segundo critérios de universidade, a partir de uma racionalidade técnica e política, hierarquizando segundo a complexidade da atenção e regionalizado conforme a distribuição populacional e do quadro de morbi-mortalidade das comunidades.

Nesse projeto é preciso repensar as formas de gerenciamento dos serviços de saúde e de enfermagem, tanto ao nível de rede básica como hospitalar, buscando uma articulação estreita entre: o atendimento prestado para as intercorrências clínicas e concomitantemente, desenvolver as ações de alcance coletivo, no controle de causas, de riscos e de danos; as unidades prestadoras de atendimento básico e os demais níveis hierárquicos.

Essa perspectiva do gerenciamento de enfermagem buscando integrar o atendimento individual curativo às ações de alcance coletivo necessita de novas tecnologias de trabalho, ou seja, incorporar e reestruturar outros conhecimentos que instrumentalizam a prática, tais como: a epidemologia, a geografia humana, antropologia, a sociologia, dentre outros.

O grande desafio para a enfermagem na construção do sistema de saúde é criar ferramentas de trabalho em direção a um modelo que valorize e defenda a vida, que busque desenvolver ações sobre os determinantes e condicionantes dos problemas de saúde ou sobre os efeitos da existência deles num território, que redefina a organização da atenção, as condutas terapêuticas e os sistemas de avaliação epidemiológica e sanitária, tendo como referência um novo paradigma assistencial, o da "promoção da saúde", com maior grau de autonomia para a categoria profissional. 


\section{EDITORIAL}

\section{LA ENFERMERÍA Y EL SISTEMA DE SALUD}

Tereza Cristina Scatena Villa*

Silvana Martins Mishima*

La discusión de la temática de enfermería y su articulación con otras prácticas de salud, tiene implicaciones en la comprensión de la constitución de un campo de conocimiento y de intervención sobre la realidad, la cual no se da de modo estático y único, al contrario, presenta historicidad.

Es así, que enfermería insertada en las prácticas sanitarias en el devenir de una sociedad en un determinado momento, reposa en una concepción que ya se presenta sobre el proceso salud-enfermedad en aquel período, del mismo modo como toma las necesidades presentes en la sociedad y de la forma como se articula al proceso de producción de servicios de salud para atender tales necesidades.

El conocimiento de enfermería se viene consolidando en la búsqueda de una intervención de forma integrada en la defensa de la vida, en el proceso sufrir/enfermar/prevenir/promover la salud individual y colectiva.

Esta concepción ha suscitado reflexiones acerca de los caminos que enfermería está recorriendo para instrumentalizar su práctica en el sistema de salud.

El desafío de la enfermería y de otras prácticas de salud en la perspectiva de construcción del sistema de salud, ha sido ocupar espacios, a fin de viabilizar los preceptos constitucionales:

- El concepto de salud como derecho universal derivado del ejercicio de una ciudadanía plena.

- La creación de un Sistema Único de Salud organizado según directrices de descentralización con un comando único en cada esfera del gobierno, la atención integral y participación popular.

- La integración de la salud en el espacio mas amplio de la seguridad social.

Este proyecto que está siendo construido busca organizar la atención a la salud según criterios de universalidad, a partir de una racionalidad técnica y

* Profesora Doctora do Departamento de Enfermería Materno-Infantil y Salud Pública da Escuela de Enfermería de Ribeirão Preto de la Universidade de São Paulo 
política, jerarquizado según la complejidad de la atención y regionalizado conforme a la distribución poblacional y del cuadro de morbi-mortalidad de las comunidades.

En este proyecto es preciso repensar las formas de gerenciamiento de los servicios de salud en enfermería, tanto al nivel de la red básica como en el área hospitalaria, buscando una articulación estrecha entre: La atención prestada a las emergencias clínicas y concomitamente, desarrollar acciones de alcance colectivo, en el control de las causas, de los riesgos y de daños; que llegan a las unidades de servicio de atención básica y los demás niveles.

Esa perspectiva del gerenciamiento de enfermería buscando integrar la atención individual curativa a las acciones de alcance colectivo, necesita de nuevas tecnologías de trabajo, o sea, incorporar y reestructurar otros conocimientos que instrumentalicen la práctica, tales como: La epidemiología, la geografía humana, antropología, la sociología, entre otros.

El grande desafío para la enfermería en la construcción del sistema de salud es crear herramientas de trabajo en dirección a un modelo que valorice y defienda la vida, que busque desarrollar acciones sobre los determinantes y condicionantes de los problemas de salud o sobre los efectos de la existencia de ellos, en un territorio, que redefina la organización de la atención, las conductas terapéuticas y los sistemas de evaluación epidemiológica y sanitaria, teniendo como referencia un nuevo paradigma asistencial, el de la "promoción de la salud", con mayor grado de autonomía para la categoría profesional. 